\title{
A ANALOGIA NOS PROCESSOS DE MUDANÇA DE VERBOS COGNITIVOS NO PORTUGUÊS BRASILEIRO ${ }^{1}$
}

Letícia de Almeida Barbosa (UFMS) Solange de Carvalho Fortilli (UFMS)

Resumo: Considerando que a analogia é um dos processos cognitivos mais básicos, que consiste na adoção de um modelo para domínios diversos, objetiva-se apresentar uma investigação sobre o papel desempenhado por ela no processo de parentetização dos verbos cognitivos no português. Os verbos cognitivos são os que expressam estados ou atividades que dão origem a percepções, conhecimentos, ideias, crenças ou julgamentos, os quais revelam processos mentais com diferentes nuances de significado. São verbos como pensar, imaginar, supor, deduzir, calcular e outros que, quando parentetizados, potencializam a expressão da subjetividade do falante funcionando como modalizadores epistêmicos. Neste sentido, a pesquisa toma por base estudos como os de Hopper; Traugott (1993), Martelotta (2010), Tavares (2003) e Fortilli (2013). Para o levantamento e análise de dados, foram selecionados casos encontrados entre os séculos XVIII, XIX e XX e XXI no Corpus do Português, bem como dados de escrita do século XXI, coletados no jornal Folha.com.

Palavras-chave: Gramaticalização; Analogia; Verbos cognitivos.

Abstract: Considering that analogy is one of the most basic cognitive processes, which consists in the adoption of a model for several domains, it is aimed to present an investigation about the role played by it in the process of parenting cognitive verbs in Brazilian Portuguese. Cognitive verbs are those that express states or activities that give rise to perceptions, knowledge, ideas, beliefs or judgments, which reveal mental processes with different nuances of meaning. They are verbs such as achar, imaginar, supor, deduzir, calcular and others that, when parentheticals, reveal the subjectivity of the speaker functioning as epistemic modalizers. By this way,

1 Título em inglês: "ANALOGY IN THE PROCESSES OF CHANGE OF COGNITIVE VERBS IN BRAZILIAN PORTUGUESE" 
the research is based on studies such as those of Hopper; Traugott (1993), Martelotta (2010), Tavares (2003) and Fortilli (2013). For the data collection and analysis, cases found between the XVIII, XIX, XX and XXI centuries in the Corpus do Português were selected, and also XXI century writing data collected in the newspaper Folha.com. Keywords: Grammaticalization; Analogy; Cognitive verbs.

\section{INTRODUÇÃO,}

Os verbos de cognição, ou de atividade mental, exprimem processos psíquicos que, no âmbito da mente, dão origens a crenças, percepções, conclusões e raciocínios relacionados a um determinado conteúdo. Este conjunto contempla verbos como pensar, achar, imaginar, supor, reconhecer, acreditar, crer, deduzir, basear, calcular e outros, que expressam diferentes processos ligados ao conhecimento e às capacidades mentais do falante. Abaixo, seguem alguns usos de tais verbos:

(1) "Imagino o sopro de angústia que atravessou a reunião dos com-teto (e que tetos!) do eixo Leblon/Lagoa." (FSP - Colunistas - Demétrio Magnoli - Com que cara o PSOL denuncia Bolsonaro enquanto celebra a ditadura chavista? - 06/01/2018)

(2) "Reconheci a voz do baiano ao mesmo tempo em que ele dizia pausadamente 'João Gilberto'”. (FSP - Colunistas - Juca Kfouri - Por triste ironia, recluso João Gilberto termina seus dias exposto - 28/12/2017)

(3) "Penso em começar a fotografar e publicar os pavorosos buracos e remendos porcos do asfalto." (FSP - São Paulo - 18 personalidades revelam promessas para melhorar a capital e a própria vida em 2018 - 14/01/2018) 
Os usos mencionados acima demonstram processos cognitivos que expressam diferentes nuances de significado, devido à atividade mental que cada um desenvolve. Em (1), nota-se que o processo cognitivo envolvido no uso do verbo imaginar faz referência ao ato de conceber uma imagem que está relacionada a uma situação ocorrida no meio político. Isso nos permite afirmar que o uso de imaginar, neste contexto, ainda se encontra arraigado ao seu sentido primordial de "formar imagem mental de algo não presente ou inventar", fato que evidencia sua forte relação com o eixo cognitivo propriamente dito.

No segundo caso, o verbo reconhecer também expressa seu significado primário, pois o falante relata que, só de ouvir, identificou a voz do "João Gilberto", embora ele tenha falado pausadamente, e esteja ausente. $\mathrm{O}$ ato de reconhecer, em seu sentido literal, está relacionado à codificação, identificação e distinção de características que estão presentes na memória do indivíduo. Na sentença em (3), com o verbo pensar, algo semelhante ocorre, pois, quando o falante diz "Penso em começar a fotografar e publicar...", ele atesta para a combinação de conhecimentos e ideias que estão presentes no seu intelecto, expressando, assim, hipóteses formuladas interiormente, em seu pensamento.

Para além do sentido literal observado nesses verbos, outros empregos vêm sendo utilizados com tais predicados. 
De verbos cognitivos, os elementos estão expressando processos mais fluidos, no sentido de se distanciarem da atividade mental específica que cada qual desenvolvia a priori. Assim, tem reforçado o traço que expressa significados modais epistêmicos, por evidenciarem traços de subjetividade e crença do falante.

Outro fato que se observa com tais verbos é o processo de parentetização, que proporciona maior liberdade sintática ao predicado e perda do argumento interno. Os verbos parentéticos funcionam por meio de uma breve suspensão da oração em curso, pois deixam de ser o núcleo da sentença, passando a atuar como modalizadores do conteúdo afirmado. Para Jubran (2006), um texto é composto por tópicos discursivos, isto é, segmentos centrados em determinados referentes. Neste sentido, quando uma informação quebra a sequência do tópico discursivo, ocorre parentetização.

As sentenças (4) e (5) mostram usos de verbos cognitivos já parentetizados:

(4) "Um lagarto, penso, jamais faria um curso de meditação." (FSP - Colunistas - Antonio Prata - Meditação e foco no macarrão - 14/01/2018)

(5) “Como, imagino, vocês devem saber, eles foram no passado influenciados por sugestões e conselhos oriundos de nós; mas essa conexão não existe mais, desde o começo do ano passado." (FSP - Poder - Livro relata colaboração britânica com tortura no Brasil na ditadura militar 14/01/2018) 
(6) "Caso a negociação evolua sem a perda de soberania nem de postos de trabalho, será um período de mudanças, que, acredito, possam ser benéficas para a empresa e para a economia da cidade." (FSP - Mercado - Clima é de silencio na fábrica da Embraer sobre a negociação com Boeing 22/12/2017)

Observa-se, acima, que os predicados cognitivos pensar, imaginar e acreditar deixam de encaixar orações completivas e passam a funcionar como um adendo, uma informação extra, que destaca o posicionamento do falante diante do conteúdo. As ocorrências supramencionadas demonstram que, juntamente com a liberdade sintática, ao se parentetizarem, entre tais verbos e a sentença escopada deixa de existir o complementizador que.

Estudos como o de Traugott; Dasher (2001) mostram uma expressão do inglês que parece, em certa medida, equivalente às que se observam no português em termos de parentetização. Há, por exemplo, o caso de I promisse you, que, quando parentetizada, ganha em expressão de subjetividade, pois tal configuração tonifica a expressão da conduta do falante diante do que ele enuncia.

Ao analisar o conjunto de verbos cognitivos que seguem na direção da parentetização, foi possível perceber que alguns são mais frequentes. Hipoteticamente isso se deve aos seus traços semânticos, que, por serem mais fluidos, não os comprometem com uma atividade mental muito específica. 
Sabendo que um subconjunto dos verbos cognitivos desenvolve processos mentais mais precisos em termos de significação, e que outro subconjunto expressa fenômenos mentais com traços semânticos mais flexíveis, observamos a possibilidade de explicar a abstratização, partindo do mecanismo de analogia, pois, por meio dele, é possível compreender a variedade de verbos cognitivos para a mesma expressão de subjetividade, via parentetização.

Sendo assim, este trabalho tem como objetivo investigar a atuação da analogia nas mudanças que envolvem verbos cognitivos no português. Estimamos que, por meio de tal mecanismo, verbos expressivos de processos cognitivos/ mentais específicos, portadores do traço modal epistêmico, têm tido reforço nessa última nuance. A parentetização torna-se, então, um processo que auxilia na marcação desse uso mais subjetivo. Para tanto, este trabalho encontrase organizado da seguinte forma: na seção que segue, apresentamos estudos que sustentam esta investigação, cujo enfoque é dado à atuação dos mecanismos de abstratização e neologização, bem como a metodologia utilizada para investigação. Na análise e discussão dos resultados, apresentamos a análise dos dados selecionados e, por fim, tecemos as considerações finais. 


\section{APORTES TEÓRICOS E METODOLÓGICOS}

\subsection{Abstratização e neologização na mudança linguística}

O processo de abstratização pode compor um conjunto maior de mudanças que afeta uma expressão. Assim, os verbos que serão analisados neste trabalho podem estar passando por um processo de gramaticalização, pois, de itens lexicais plenos, tais elementos vem apresentando perda de traços lexicais específicos de cada processo mental, preservando aqueles que expressam modalidade, que é uma noção mais abstrata.

Por gramaticalização, doravante GR, compreende-se um processo pelo qual itens lexicais passam a desempenhar funções gramaticais, e itens gramaticais possivelmente aumentam sua gramaticalidade. A GR, embora forneça novos usos a formas já existentes no léxico da língua, não ocorre de forma abrupta. Hopper (1998) sugere que a mudança, via $G R$, pode ser representada pela seguinte fórmula: $A>A / B$ $>$ B. Seguindo esta representação, é possível compreender que há uma gradualidade no processo, pois, por meio de uma extensão funcional, as possibilidades de uso vão sendo ampliadas. O estágio $A / B$ fornece a evidência de que não existem momentos totalmente delimitados, mas estágios intermediários, em que há a coexistência de formas em competição. 
Autores como Hopper \& Traugott (1993) mostram a possibilidade de conceber o processo de GR de modo mais amplo, pois consideram que o item gramaticalizado nem sempre se tornará um clítico ou atingirá morfema zero na escala da mudança, como alguns estudos afirmam (HEINE, 1991). Em Traugott \& Heine (1991), já se assinalava que os itens candidatos à GR não são arbitrariamente selecionados no sistema linguístico. Sobre isso, Tavares (2003) anuncia que há um conjunto de elementos lexicais que são mais propícios a atingir maior grau de gramaticalidade, dentre eles, ganham destaque os verbos que expressam processos mentais, os locativos e os quantificadores.

Dentre os mecanismos atuantes no processo de GR, salientamos a transferência metafórica. Por meio dela, verbos com diferentes traços semânticos podem ser associados entre si, via captação de algum traço em comum.

Assentando-se nas premissas de Traugott \& Heine (1991), consideramos metaforização um processo cognitivo que proporciona ao falante partir de experiências do mundo biossocial, para representar ações que não são facilmente recuperadas, devido ao grau de abstratização que possui. De acordo com os autores, o uso da metáfora conceptual pode ser descrito por meio do seguinte cline:

$$
\text { PESSOA > OBJETO > PROCESSO > ESPAÇO > TEMPO > QUALIDADE }
$$


Observando a trajetória acima, nota-se que a metaforização pode ocorrer a qualquer momento, porém a relação estabelecida entre tais domínios segue o sentido unidirecional da mudança, por seguir sempre do mais concreto ao mais abstrato, da esquerda para a direita, como a relação de espaço e tempo, em que tempo sempre é codificado em termos de localização espacial. Ao ocorrer transferência metafórica, há um aumento do contexto de uso, devido à abstratização do significado inicial. Um exemplo de tal processo é o do verbo achar, que, de um sentido mais concreto "encontrar", passou por diversos estágios de mudança, até apresentar comportamento semelhante ao de advérbio modalizador epistêmico, seguido de parentetização.

Casseb-Galvão (2000) defende a existência de um continuum, em que o verbo achar, portador de nuance epistêmica, apresenta quatro diferentes significados:

achar1: encontrar

achar2: apreciar

achar2': considerar

achar3: opinar

achar4: modalizar (esse último pode apresentar-se na forma parentetizada).

Ainda segundo Casseb-Galvão (2000, p.57), a metáfora parece ser o principal desencadeador do processo, pois de 
um domínio mais concreto e palpável, é captado um sentido mais abstrato, que é o da modalidade, ou seja, o das ideias, das opiniões e crenças.

Pensando nos processos que envolvem a abstratização de significados, é possível notar a atuação de dois mecanismos que proporcionam um maior alcance de contextos: a generalização e a analogia. Conceitos já existentes são mapeados para representação de conceitos inexistentes, o que proporciona, ao item em questão, perda dos traços semânticos de origem. Tal processo está intimamente relacionado à analogização que, de acordo com Gonçalves et al (2007, p.49), se refere à atração de formas preexistentes por outras construções também já existentes no sistema, envolvendo inovações ao longo do eixo paradigmático.

Para além da abstração metafórica, que está relacionada ao mapeamento conceitual, ou seja, o uso de objetos mais concretos para compreensão e conceitualização de objetos mais abstratos, Traugott \& Heine (1991) destacam outros dois tipos de abstratização: a "generalizante", em que ocorre redução de traços semânticos centrais, e a "isolante", que separa uma propriedade ou traço particular que não é o mais representativo de determinado elemento. Com a ampliação do significado, o termo passa a ser generalizado, na medida em que mais falantes vão se apropriando do novo 
sentido, até que esta nova representação se convencionaliza e passa a ser recuperada com o novo sentido em contextos específicos. Vale mencionar que, para a ocorrência de tais processos, uma forma candidata à mudança pode seguir os passos de outra, que já experimentou tais alterações, desde que tenha traços análogos aos dela.

A fim de relacionar os processos que atingem diferentes verbos cognitivos do português, foram selecionadas ocorrências com os verbos achar, acreditar, deduzir e calcular, encontrados entre os séculos XVIII ao XXI no Corpus do Português. A hipótese deste trabalho é que, a exemplo de verbos cognitivos mais fluidos, em que não há um processamento cognitivo muito específico, outros, que apresentam nuances semânticas mais peculiares, estão sendo levados, via analogia, ao uso parentetizado. Por esse motivo, selecionamos dois verbos portadores de traços semânticos mais genéricos (achar e acreditar, respectivamente) e dois com traços mais ligados à especificidade de uma atividade mental determinada (deduzir e calcular).

A metodologia envolve a detecção de ocorrências que demonstrem maior proximidade com o eixo da cognição, em que os sentidos dos verbos expressam uma experiência mental específica, bem como daquelas em que a postura epistêmica do falante com relação ao que é dito se mostra mais saliente. 


\section{ANÁLISE E DISCUSSÃO DOS RESULTADOS}

Adotamos, neste trabalho, o conceito de analogia como uma atração por formas já existentes estendidas para diversos contextos de uso, o que ocorre quando diferentes formas passam a desempenhar semelhantes funções. Analogia, portanto, não é sinônimo de igualdade. Retomando a hipótese de que, por meio de tal mecanismo, alguns verbos estão apresentando fortalecimento do seu traço modal epistêmico, chegando à parentetização, foi feita uma coleta de dados no Corpus do Português com intuito de observar, de maneira mais geral, a frequência dos usos supramencionados. Embora não tenha sido empreendida uma pesquisa quantitativa exaustiva, foi possível observar, dentre os séculos XVIII ao XXI, os verbos cognitivos mais recorrentes na forma parentetizada.

O critério de análise baseou-se nos traços semânticos de cada verbo. Assim, para explicar o fenômeno de analogização ocorrido entre tais predicados, foram selecionados apenas dois verbos (achar e acreditar) que apresentam traços semânticos mais fluidos, no sentido de não denotarem um processo mental com traços muito delimitados, e dois verbos (deduzir e calcular) que, embora em processo de abstratização, encontram-se bastante ligados a uma 
atividade mental mais específica. Para tanto, o gráfico abaixo representa as 27 ocorrências com o verbo achar, 18 ocorrências com o acreditar, 12 ocorrências com o verbo deduzir, e 5 ocorrências com o calcular.

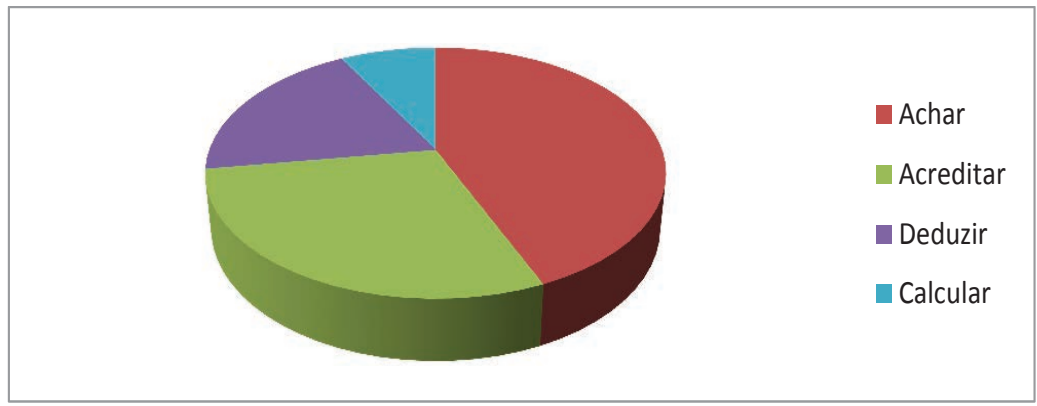

Gráfico 1 - Verbos cognitivos parentéticos no Corpus do Português

Das ocorrências encontradas, pode-se perceber que o verbo achar é o mais frequente na forma parentetizada. Parece-nos, assim, que esse verbo é aquele em que o falante mais reconhece a possibilidade de exprimir a forma como se relaciona com o conteúdo proposicional, ou seja, ele já tem seu traço modal bastante reforçado no português atual. Os verbos acreditar, deduzir e calcular estão sendo apresentados de forma semelhante, por contarem também com esse traço: o da postura epistêmica do falante (TRAUGOTT, 2012).

Seguem abaixo, algumas ocorrências encontradas:

(1) "Escrevo sobre negros e farroupilhas e também sobre imperadores: D. Pedro II, O Príncipe Regente é o nome da 11á ópera. Pedro II foi o maior presidente que tivemos, acho." (190r:Br:Intrv:ISP) 
(2) "Uma geração que, eu acho, amou muito esse país. Que amou a pátria e por isso escreveu, para mostrar o que se passava com ela." (190r:Br:Intrv:ISP)

(3) "Estou partindo para captar recursos pela Lei do Audiovisual. O projeto, acredito, está muito bonito e aborda apenas um ano da vida de Castro Alves, 1868, interligado com vários outros acontecimentos importantes da política brasileira, como a Guerra do Paraguai." (190r:Br:Intrv:ISP)

(4) "Assim como os primeiros a visitarem uma exposição impressionista reclamaram que a falta de contorno, conseqüência de "supostas extravagâncias cromáticas", não permitia identificar as figuras representadas, a argumentação dificilmente permite uma experiência estética, ou convence sobre ela. O mesmo vale, acredito, para o filme, enquanto objeto de estudo específico." (19Ac:Br:Lac:Thes)

(5) “De aí, deduzo, ou eles aprenderam bem rápido, ou os fabricantes instalados aqui não ligam muito pra essas besteiras de durabilidade." (noticiasautomotivas.com.br)

(6) "Ele está na rua há anos, deduzo." (arcauniversal.com)

(7) "Quem é que se quer apaixonar por uma pessoa que não corresponde a esse amor, estando ainda a recompor-se de uma separação recente?? Ninguém, (calculo eu)...ninguém gosta de sofrer!" (portaldoamor.com.br)

(8) "E tem gostado? Naturalmente que sim. Eu calculo." (slideshare.net - O país do carnaval - Jorge Amado)

(9) "Durante este tempo, Ovando havia se aproximado demais, quase ombro a ombro, o que muito me preocupou por que meu chofer era um indiozão de quase dois metros de altura e um peito largo que, calculo, dava o dobro do meu." (memorial.org.br - crônica - Reflexões de um viajante - Juan Carlos Onetti) 
Ao observar acima as ocorrências com o verbo achar, é possível recuperar o quarto uso proposto por Galvão (2000), pois, de verbo pleno e codificador de uma ação concreta, que é o ato de descobrir/encontrar, o verbo achar, nas ocorrências (1) e (2), passou por alguns estágios de abstratização, chegando a ser utilizado na configuração parentética, em que a postura epistêmica daquele que fala sobressai em relação ao seu sentido de denotar uma experiência mental peculiar. Nota-se que na sentença em (1), o falante suspende o tópico em curso, para marcar o seu nível de comprometimento com a afirmação, fato que se torna evidente em "Pedro Il foi o maior presidente que tivemos, acho.", em que o achar perde o segundo argumento, que, neste contexto, seria a oração subordinada substantiva objetiva direta, introduzida pelo complementalizador que. Posteriormente, em (2), além de o verbo aparecer parentetizado, ele apresenta o primeiro argumento, o pronome pessoal do caso reto: Uma geração que, eu acho, amou muito esse país, assim, a subjetividade fica bem marcada, na medida em que, além de recorrer ao uso de um verbo altamente abstratizado, e que faz referência à modalidade epistêmica, é utilizado o pronome, que sinaliza ainda mais a pessoalidade do comentário.

Em (3), o verbo acreditar, que já aparece bastante abstratizado, também é utilizado como parentético 
epistêmico. O processo cognitivo de acreditar, que originalmente está ligado à crença em algo concreto ou abstrato, é parentetizado com frequência. Acreditar, inicialmente, fazia referência à ação de dar créditos e ter confiança, isto é, atribuir valor ou confiabilidade a algo ou alguém. Com o uso mais generalizado, houve a mitigação desse seu sentido inicial, o que o levou à saliência do traço epistêmico, em que o que se marca é a relação do falante com a proposição.

O mesmo ocorre em (4), quando, em posição medial, o falante insere o verbo acreditar, com intuito de modalizar, epistemicamente, o tópico em curso. Percebe-se, em " $O$ mesmo vale, acredito, para o filme, enquanto objeto de estudo específico", que o verbo não compõe o quadro de referentes da oração, apenas é inserido como um elemento extra, para relativizar o conteúdo afirmado. Nesse uso, em configuração parentética, a ideia primordial de atribuir confiança ou crena a alguém não se apresenta, dando lugar a um traço do verbo, aquele que permite ao usuário da língua não se comprometer com a proposição.

O processo de analogização pode ser constatado, na medida em que observamos o recrutamento de predicados que expressam processos mentais mais concretos a um domínio um pouco distinto: o eixo epistêmico. Por meio da análise destes verbos, consideramos que, com base na 
construção parentética modal, diferentes verbos cognitivos estão trilhando a mesma trajetória. A metáfora proporciona ao falante fazer uso de elementos diferentes, para codificação de um mesmo significado, que, neste caso, é o da modalização epistêmica.

Em ocorrências posteriores, notamos os verbos deduzir e calcular como exemplos de verbos menos frequentes, cujas propriedades semânticas evocam um processamento mental mais específico e concreto. Com base nesta extensão semântica, notamos que o verbo deduzir, que é típico de raciocinar, inferir e concluir, passa a ser codificado, nesses contextos, como um verbo epistêmico, visto que proporciona interpretações semelhantes aos demais, mais típicos desse uso: achar e acreditar. Assim, em (5), "De aí, deduzo, ou eles aprenderam bem rápido, ou o fabricantes instalados aqui não ligam muito pra essas besteiras de durabilidade", pode-se observar duas orações coordenadas, cuja primeira, vem antecedida de um parentético modal, que permite interpretar o falante como fonte de evidência da informação. Nota-se que o conteúdo da proposição não é ligado ao contexto de deduções lógicas, ou seja, não se está diante de uma dedução propriamente dita, que conta com uma experimentação mental específica para ocorrer. O que se tem é a marcação de que o falante não tem certeza sobre a verdade do que diz. 
Na ocorrência em (6), embora o verbo deduzir apareça em posição final, o que é praxe das ocorrências encontradas, notamos, mais uma vez, a necessidade de o falante se posicionar diante do conteúdo declarado. Ao dizer "Ele está na rua há anos, deduzo", torna-se notório o fato de o verbo não retomar uma conclusão, mas sim sua percepção, sua experiência e o seu conhecimento acerca da proposição.

Por último, mas não menos importante, observamos o uso do verbo calcular. Este, assim como o deduzir, não é um forte codificador de crença e opinião, o que pode ser constatado por meio de seus usos iniciais. Calcular compõe o quadro dos verbos que expressam processos mentais mais delimitados, pois evidencia uma atividade mental diferente de todas aquelas expressas por outros verbos. Embora haja poucas ocorrências na configuração parentética, é possível observar uma abstratização, com notória saliência do sentido epistêmico, o que aponta para atuação da analogia. Em (7), quando o falante afirma "Ninguém, (calculo eu)... ninguém gosta de sofrer!", percebemos que, apesar de as experiências levarem-no a pensar que as pessoas não se alegram com o sofrimento, por não ser algo comprovado, ele parentetiza a oração, utilizando o verbo calcular, que permite ao ouvinte ter acesso ao nível de comprometimento com a verdade do conteúdo. 
O mesmo ocorre em (8), visto que o verbo se afasta do eixo que expressa quantificação e raciocínio lógico matemático, passando a se aproximar do eixo epistêmico, com a expressão de subjetividade. Ao responder "Naturalmente que sim. Eu calculo." o verbo não se porta como um encaixador de oração completiva, uso que, em geral, favorece seu sentido primário, pois passa a ter maior liberdade sintática, visto que pode se parentetizar em qualquer ponto da oração.

Com base no processo metafórico, a abstratização se evidencia, na medida em que os traços semânticos de origem deixam de ser recuperados, e o elemento passa a expressar um efeito bastante semelhante àqueles que se fazem fortemente presentes em verbos com sentido mais generalizado, como achar e acreditar. Em (9), temos mais um caso em que, tomando como base verbos de processos menos específicos, o falante seleciona o calcular para relativizar a verdade do conteúdo afirmado. Quando é dito "Ovando havia se aproximado demais, quase ombro a ombro, o que muito me preocupou por que meu chofer era um indiozão de quase dois metros de altura e um peito largo que, calculo, dava o dobro do meu", por meio de um conhecimento inferido e aproximativo, o falante faz sua afirmação sem se comprometer de todo com seu conteúdo.

Quantoàsquestões morfológicas, os verbos parentetizados aparecem na primeira pessoa do singular, o que explica o 
alto grau de subjetividade, e em tempo presente, em que o falante pode expressar como se relaciona com o conteúdo proposicional. Tais características confirmam a hipótese mencionada neste trabalho, pois, para se parentetizar, além de expressar uma atividade cognitiva, o verbo deve ter traços modais. A exemplo de verbos que já tiveram esse sentido salientado via parentetização, como achar e acreditar, outros vão sendo recrutados, por poderem atuar de maneira análoga, como deduzir e calcular. Esses últimos, portadores de traços cognitivos mais específicos, por terem ao menos um traço modal, permitem-se parentetizar, atuando como afterthought, que permite ao emissor se posicionar diante do que é dito.

\section{CONSIDERAÇÕES FINAIS}

Retomando as questões discutidas até aqui, pode-se depreender que a analogia é um mecanismo que auxilia na explicação da variedade de formas para a expressão de subjetividade no português, especificamente, no que diz respeito à seleção de verbos cognitivos. Verbos com traços semânticos mais gerais e que tendem a ser mais frequentes estão servindo de modelo para a atuação de verbos cujos traços semânticos eram, primordialmente, mais definidos. Neste sentido, embora haja diferentes nuances de significados, o processo de analogização proporciona que 
verbos com sentido mais centrado em um processamento mental específico sejam recrutados para o uso parentetizado, passando a desempenhar funções semelhantes: aquelas mais voltadas à expressão da postura epistêmica.

Desse modo, tais verbos atingem um maior grau de gramaticalidade, com a abstratização de significado, pois, de um domínio conceptual mais restrito, passam a desempenhar função ainda mais abstrata: a relação do enunciador com o grau de certeza que detém sobre seu enunciado.

\section{REFERÊNCIAS}

CASSEB-GALVÃO, Vânia (1999). O achar no português do Brasil: um caso de gramaticalização. Dissertação (Mestrado em Linguística). Campinas: UNICAMP.

(2000). "A atuação de mecanismos desencadeadores de processos de gramaticalização". In: . O achar no português do Brasil: um caso de gramaticalização. (Dissertação de Mestrado) SCRIPTA, Belo Horizonte, (7), p.44-59, 2ㅇ sem.

FORTILLI, Solange de Carvalho. (2013). Predicados matrizes adjetivais de orações subjetivas no português brasileiro: Gramaticalização e Dessentencialização. 163f. (Tese - Doutorado em Estudos Linguísticos). UNESP/IBILCE. São José do Rio Preto.

GIVÓN, Talmy. (1971) Historical Sintax anda Synchronic Morfology: an Archaelogist's Field Trip. Papers from the 7th. Regional Meeting. Chicago: Chicago Linguist Society.

GONÇALVES, Sebastião Carlos Leite (2003) Gramaticalização, modalidade epistêmica e evidencialidade: um estudo de caso no português do Brasil. 250f. (Tese - Doutorado em Linguística) - Instituto de Estudos da Linguagem, Universidade Estadual de Campinas, Campinas. 
HOPPER, Paul; TRAUGOTT, Elizabeth (1993) Grammaticalization. Cambridge, UK: Cambridge University Press.

HOPPER, Paul (1998). Emergent grammar. In: TOMASELLO, M. (Ed.). The new psychology of language. v. 1. Mahwah, New Jersey: Lawrence Erlbaum. p.155-176.

JUBRAN, Clélia Cândida Abreu Spinardi; KOCH, Ingedore Grunfeld Villaça. (Orgs) (2006). Gramática do Português Culto Falado no Brasil. Construção do texto falado. Campinas: Editora da Unicamp.

MARTELOTTA, Mário Eduardo (2010). "Unidirecionalidade na gramaticalização". In: VITRAL. Lorenzo; COELHO. Sueli (Org). Estudos de Processos de Gramaticalização em Português: metodologias e aplicações. 1.ed. Campinas: Mercado de Letras.

TAVARES, Maria Alice (2003). A gramaticalização de E, Aĺ, DAÍ, e ENTÃO: estratificação/variação e mudança no domínio funcional da sequenciação retroativo-propulsora de informações - um estudo sociofuncionalista. (Tese - Doutorado em Linguística) Programa de Pós-Graduação em Linguística da Universidade Federal de Santa Catarina.

TRAUGOTT, Elizabeth Closs (2012). "Intersubjetification and clause periphery". English Text Constructions. 5(1), p.7-28.

(2003). "From subjectification to intersubjectification". In: HICKEY, R. Motives for Language Change. Cambridge, UK: Cambridge University Press. p.124-139.

TRAUGOTT, Elizabeth Closs; DASHER, Richard (2001). Regularity in semantic change. Cambridge: Cambridge University Press.

Letícia de Almeida Barbosa é Graduada em Letras - Português/Inglês (2013-2016) pela Universidade Federal de Mato Grosso do Sul, campus de Três Lagoas (CPTL). Mestranda no Programa de Pós-Graduação em Letras (2017-2019), com ênfase em descrição e análise linguísticas na perspectiva funcional cognitivista, sob a orientação da Prof. a Dr.a Taísa Peres de Oliveira (UFMS), e integrante do Grupo de Estudos Sociofuncionalistas, CNPq - Conselho Nacional de Desenvolvimento Científico e Tecnológico. 
Solange de Carvalho Fortilli é Graduada em Letras (Português-Francês) pela Universidade Estadual Paulista, Mestre e Doutora em Estudos Linguísticos pela mesma Instituição. É professora adjunta do campus de Três Lagoas da Universidade Federal do Mato Grosso do Sul, onde atua no ensino de graduação nas áreas de Morfologia e Sintaxe da Língua Portuguesa. Em nível de pós-graduação, compõe o quadro docente do Mestrado Profissional em Letras (PROFLETRAS) e é responsável pelas disciplinas referentes à gramática do português e à variação linguística e pela orientação de dissertações a elas relacionadas. Integrante também do Programa de Pós-Graduação em Letras, atua na linha de Estudos Sociofuncionalistas e desenvolve, sobretudo, os temas mudança linguística, gramaticalização e subjetivização.

Recebido em 04 de fevereiro de 2018. Aprovado em 25 de abril de 2018. 